Thorax (1965), 20, 467.

\title{
Unexpected electrocardiographic recordings in bronchoscopy under general anaesthesia
}

\author{
F. VAN NOUHUYS \\ From the Department of Anaesthesiology, Rode Kruis Ziekenhuis, The Hague, The Netherlands
}

It has long been known that intubation, endotracheal suction, and extubation have on occasion been associated with significant changes in the electrocardiographic pattern, including cardiac arrest. Burstein, LoPinto, and Newman (1950) described electrocardiographic disturbances in 74 of 109 patients during endotracheal intubation following general anaesthesia with various usual techniques. The majority consisted of sinus tachycardia. According to Rollason (1964), the many papers written on these changes showed that those most frequently observed were tachycardia, bradycardia, atrial, nodal, and ventricular extrasystoles, atrial fibrillation, nodal rhythm, heart block, decrease in the height of the $\mathrm{T}$ wave, and depression of the ST segment.

There is no reason to suppose that in bronchoscopy under general anaesthesia the described abnormalities should not arise. However we have been unable to find many references to the subject in the literature available to us. Burman and Gibson (1963) report findings in 62 bronchoscopies, notably under local anaesthesia. Fifty-nine of the patients developed a tachycardia; in 49 this began when the bronchoscope touched the trachea, carina, or bronchi ; 22 patients showed significant arrhythmias, including premature atrial contractions, nodal rhythm, premature ventricular contractions, and wandering pacemaker. Fairley, quoted by Hewer (1963), believed that hypercarbia was responsible for the increased incidence of cardiac irregularities which he observed in bronchoscopy under general anaesthesia. Rollason (1964) was of the opinion that endoscopy (e.g., laryngoscopy, bronchoscopy, or oesophagoscopy) often produced a marked pressor response, which may put a considerable strain on a diseased heart, particularly if associated with anoxia and $\mathrm{CO}_{2}$ retention. According to this author the E.C.G. may then reveal an arrhythmia and/or changes in the ST segment and $T$ wave, suggesting myocardial anoxia, and on occasion left ventricular strain.
Bronchoscopy under general anaesthesia may give rise to hypoxaemia and hypercarbia. These occur at moments when the manipulations of the bronchoscopist make the correction, by ventilation, of respiratory insufficiency impossible. This insufficiency is often caused or enhanced by the use of muscle relaxants. Hypoxaemia can sometimes be prevented by the continual insufflation of oxygen, but this cannot prevent the development of hypercarbia.

We studied 16 bronchoscopies under general anaesthesia. Premedication was $75 \mathrm{mg}$. pethidine, $0.5 \mathrm{mg}$. atropine; induction with $0.5 \mathrm{~g}$. thiopentone. An intravenous drip of succinylcholine chloride was continued until relaxation of the jaw was complete; the patient was hyperventilated with oxygen. Topical analgesia with tetracaine $2 \%$ followed, and ventilation was restarted until adequate respiration had returned. After the bronchoscope had been introduced, a side-tube specially made for this purpose was connected with the anaesthetic machine, and a high flow of nitrous oxide-oxygen, or oxygen alone, with halothane was given. The patient was thus breathing spontaneously. Succinylcholine chloride was administered sparingly and only if required. Ventilation was possible by bag-squeezing after blocking the aperture of the bronchoscope when necessary. Before induction of anaesthesia the patient had been connected to an oscilloscope ${ }^{1}$ and to an electrocardiograph. ${ }^{2}$ As often as was considered necessary the oscilloscope tracings could be recorded with the electrocardiograph.

Only nine patients showed normal tracings or only minor abnormalities. In two, right ventricular extrasystoles developed; in another two patients left ventricular extrasystoles, and in one an intermittent left bundle-branch block occurred. The unexpected findings, however, were that in two patients changes in the ventricular complexes developed $\left(V_{1}\right.$ recording), exhibiting the charac-

1Videograph M.I.E. 2Sanborn Visette 


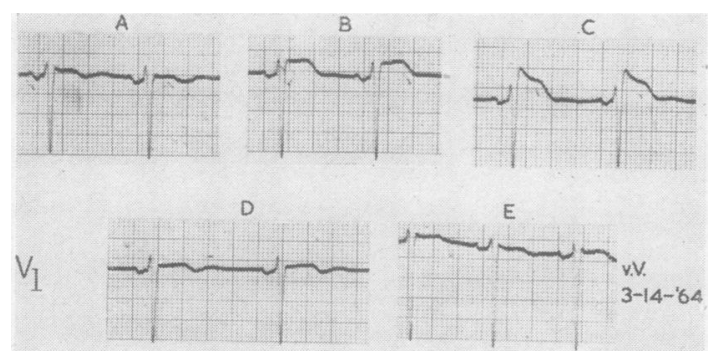

FIGURE $B$ and $C$ : Characteristics of an acute cor pulmonale; for further details see text.

teristics of an acute cor pulmonale. Figure A shows a recording before the disturbance took place, Figures $\mathrm{B}$ and $\mathrm{C}$ the abnormality itself, Figure $\mathrm{D}$ the situation three minutes later, and Figure $\mathrm{E}$ was recorded towards the end of the operation. In the second patient the same picture was seen, though it was less pronounced. In this case a period was also recorded when extrasystoles occurred, which disappeared after ventilation with oxygen. As to the mechanism which provoked the appearance of acute cor pulmonale, we can only guess how it was caused. It should probably be considered as a serious complication. It must be stated, however, that at the time the abnormality was registered the patients showed no clinical signs of distress: there was an apparently adequate spontaneous respiration, and cyanosis was absent.

Taking into consideration the important part played by hypoxaemia and hypercarbia in the development of cardiac abnormalities during general anaesthesia, it appears that the safest way to administer general anaesthesia for bronchoscopy is to make the patient apnoeic from the start of the operation, and to ensure ventilation by positive-negative pressure applied to the chest wall and abdomen, preferably by a wrap-round mechanical cuirass respirator as described by Silverblatt and Rueger (1963) and Hewer (1963). In this way maintenance of physiological respiration is ensured.

I am grateful to Professor Dr. D. Durrer and Professor Dr. J. W. Duijff for their help in the preparation of this paper.

\section{REFERENCES}

Burman, S. O., and Gibson, Th. C. (1963), Bronchoscopy and

cardiorespiratory reflexes. Ann. Surg., 1, 134. Electrocardiographic studies during endotracheal intubation. I. Effects during usual routine technics. Anesthesiology, 11, 224.

Hewer, C. L. (1963). Recent Advances in Anaesthesia and Analgesia, 9 th ed. Churchill, London.

Rollason, W. N. (1964). Electrocardiography for the Anaesthet ist. Blackwell, Oxford.

Silverblatt, B. L., and Rueger, R. G. (1963). Endosccpy under general anesthesia. Laryngoscope (St. Louis), 73, 749. 